\title{
A Promoção de Democracia Liberal pela OEA: o que esperar?
}

\author{
Alan Gabriel Camargo \\ Universidade Nacional de Brasília
}

\section{Introdução}

O salto quantitativo de regimes democráticos marcou o cenário latino-americano das últimas décadas. De acordo com o relatório Authority Trends, publicado pelo Polity IV (2017), 14 países investigados em 1980 eram considerados Autocracias, ao passo que as Anocracias e as Democracias registravam, igualmente, 5 ocorrências cada. No decorrer de 15 anos, o número de Autocracias foi reduzido para 2, ao mesmo tempo em que as Anocracias registraram 6 e as Democracias 16 casos. Houve, nesse sentido, o aumento de $220 \%$ no número de regimes democráticos.

Esta proliferação insere-se no movimento conceituado por Samuel Huntington (1994) como Terceira Onda de Democracias. Em termos sucintos, este fenômeno converteu os antigos autoritarismos em democracias representativas, por conta de fatores domésticos e internacionais ${ }^{1}$. Como não haveria indícios de reversões, a Terceira Onda seria numérica e enfaticamente superior aos movimentos anteriores, confirmando a máxima do Fim da História segundo Fukuyama (1991) ou, melhor dizendo, o clímax no qual os homens teriam se convertido à ideologia capitalista e ao "universalismo" da Democracia Liberal.

Para certos teóricos (O’Donnell, 1996, 2000; Diamond, 1999), porém, a Terceira Onda deve ser investigada em sua capacidade de consolidar as democracias insurgentes, de modo a permitir o exame de sua qualidade. Guillermo O’Donnell $(1996,2000)$ é referência nesse debate, para quem o processo de consolidação democrática na América Latina, na contramão das expectativas liberais, resultou em Democracias Delegativas. Segundo este conceito, há, na região, instituições formais como as eleições regulares e os mecanismos de controle de poder - e informais - clientelismos, usurpação de cargos e baixa transparência política -, combinadas no mesmo processo de consolidação política. Longe de deturpada, a Democracia Delegativa é entendida, para o autor, como experiência típica do desenvolvimento social e político do continente.

Mas o fato é que, apesar desse reconhecimento, ainda se coloca a versão liberal da Democracia como parâmetro acadêmico e internacional para mensuração da qualidade e legitimidade política. Desse feito é que a América Latina passou a ser objeto propício ao exame dos desafios para consolidar tais regimes, ensejados desde o Pós-Guerra Fria pelas forças externas.

Concomitantemente ao grande otimismo quanto à promoção de Democracia Liberal, tais países enfrentaram abalos em suas instituições, representando verdadeiras crises políticas. Ocorrências como queda de presidentes, Golpes, Estado de Emergência, guerras civis, entre outras, tornaram-se crônicas no hemisfério e colocaram à prova o funcionamento e a consolidação, nos parâmetros liberais, das democracias emergentes.

\footnotetext{
1 Tais como deslegitimação das ditaduras; desenvolvimento econômico e aumento nos padrões de vida; reformas dogmáticas na Igreja Católica; alterações na política externa de certos atores - como os Estados Unidos, por exemplo -, além do efeito contagioso internacional (Huntington, 1994).
} 
O fato é que, mesmo com as forças que perturbam a estabilidade desse processo, certas iniciativas são destinadas à reversão das crises. Dentre elas, optamos pela análise da promoção de democracia pela Organização dos Estados Americanos (OEA). A instituição, desde meados dos anos 1990, dispõe de um Regime próprio (Camargo, 2013), dotado não somente de princípios e normas, mas de mecanismos de prevenção e reversão das ocorrências que suspendam a ordem da Democracia Liberal.

Tomando como base o apresentado, e levando em consideração o pressuposto de que as democracias podem ser consolidadas também por vias externas aos Estados (Castro Santos, 2001, 2010; Farer, 1996; Whitehead, 2005), o artigo em questão tem como objetivo analisar os resultados da promoção de democracia, entre 1990 e 2018, após o envolvimento da OEA nos contextos de crises políticas do hemisfério, extraindo dele uma inferência a partir do exame dos padrões e regularidades desse processo.

\subsection{Metodologia}

Para este fim, a pesquisa levantou 31 casos de crises políticas distribuídos no recorte temporal mencionado. $\mathrm{O}$ critério de seleção buscou identificar ocorrências que: 1) contemplassem regiões distintas da América Latina, de modo a abarcar os diferentes contextos sociais, políticos e econômicos; 2) estivessem distribuídos de modo mais ou menos uniforme ao longo do recorte entre o primeiro semestre de 1990 e o último de 2018 - chamado aqui de Pós-Guerra Fria; 3) sensibilizassem a Assembleia Geral, o Conselho Permanente ou a Reunião de Consulta dos Ministros das Relações Exteriores da OEA e apresentassem, por parte de algum deles, respostas pontuais para a crise.

Uma vez selecionada a amostra, a pesquisa qualificou seus casos segundo a natureza das crises políticas. Para tal empreendimento, aplicou-se a classificação trazida por Coutinho (2006), que categoriza as instabilidades políticas da região segundo Golpes, Interrupção do Mandato Presidencial, Estado de Emergência, Revoltas Sociais e Guerra Civil.

O passo seguinte buscou identificar as respostas dadas pela OEA para reverter cada crise. Tal verificação constatou uma gama ampla de instrumentos de promoção de democracia, que vão, desde apoio ou condenação retórica, até a mecanismos mais severos, como sanções, encaminhamento ao Conselho de Segurança das Nações Unidas (CSNU) e suspensão da participação organizacional.

Por fim, os resultados de cada envolvimento da OEA foram avaliados de acordo com o Liberal Democracy Index, instrumento desenvolvido pelo V-DEM (2018a). Sem fornecer um índice unificado para medir a qualidade da consolidação democrática, o Instituto emprega diferentes mecanismos para entender tal processo, que priorizam, cada um, princípios-chave como: eleitoral, liberal, majoritário, consensual, participativo, deliberativo e igualitário. Neste trabalho, empregamos o índice que avalia a dimensão liberal, uma vez que se entende ser este o modelo legitimado pela maior parte da literatura e dos movimentos de promoção de democracia desde o Pós-Guerra Fria, além de compor a percepção ontológica da OEA quanto à natureza democrática, como será demonstrado ao longo do artigo.

Nesse sentido, o Liberal Democracy Index é composto pelas dimensões da democracia eleitoral, de um lado - abordados neste trabalho como modelo procedural mínimo - e pelas dimensões liberais de democracia, tais como igualdade perante à lei, liberdades individuais, constrangimentos do 
Judiciário sobre o Executivo e constrangimentos do Legislativo sobre o Executivo. Cada uma das dimensões desdobra-se em indicadores que, somados compõem o referido Index. A escala do mesmo varia entre 0 e 1 , sendo que, quanto mais próximo ao último valor, maior a qualidade liberal da democracia $^{2}$.

\subsection{Estruturação}

$\mathrm{O}$ artigo apresentado se estrutura em três partes. Na primeira, resgata-se o debate, dentro da teoria democrática, quanto à construção do conceito da Democracia Liberal. Em seguida, retoma a compressão, por parte da literatura, quanto à possibilidade de se promover este regime por vias internacionais, especialmente após a Guerra Fria.

Considerando a OEA como uma dessas forças promotoras de democracia, a segunda etapa do trabalho descreve a construção da condicionalidade da democracia, tomada não somente como normatividade, mas, também, como fundamento que enseja os envolvimentos da Organização em situações de crise política. Nesta etapa, resgatam-se os traços liberais de democracia, como propostos por Diamond (1999) e os comparam ao modelo defendido pela OEA (2001). Chega-se à conclusão que, embora não explícita nesses termos, a fórmula de democracia empreendida pela Organização é alinhada à ontologia liberal, tal como desenhada pela literatura da área.

A terceira etapa do trabalho avalia a eficácia da OEA em gerar Democracias Liberais de qualidade, segundo o Índice V-DEM, após sua intervenção nas crises dos anos 1990, 2000 e 2010. Isto posto, a partir dos resultados da pesquisa, constata-se na conclusão que, primeiramente, há variações na forma como a OEA responde às crises democráticas dependendo da natureza do abalo político e das informações à disposição e, em segundo lugar, que suas intervenções não encaminham o resultado ótimo esperado pela Organização, qual seja: a Democracia Liberal de alta qualidade. A tendência notada é de regimes que se mantêm, em sua maioria, distanciados dos valores de alta qualificação, segundo o Índice já apontado.

\section{Definindo os conceitos: a democracia liberal e sua promoção no Pós-Guerra Fria}

Embora as experiências democráticas datem da Antiguidade, foi no século XX que a democracia assumiu um novo alcance para se fixar como modelo predominante de organização política no Ocidente. O novo contexto, marcado pela complexidade das sociedades industriais, organizadas em Estados e processadas por formas burocráticas, passou a validar a democracia como procedimentos eleitorais que encaminhariam a representação política. O debate traçado no Pós-Guerra reuniu perspectivas que comungavam o anseio de definir o melhor formato para que a democracia se adequasse à nova realidade, e os pleitos eleitorais foram reconhecidos como mecanismos exitosos para processar as demandas sociais (Laisner, 2009).

Uma das teses mais influentes dessa geração foi a perspectiva de Joseph Schumpeter (1961). O autor não apenas consolida a representação como única forma para que os cidadãos participassem do processo decisório, como também postula ser as eleições o momento nevrálgico através do qual os interesses divergentes disputariam a vitória do pleito. Nas palavras de Schumpeter, a democracia configura um “[...] sistema institucional, para a tomada de decisões políticas, no qual o indivíduo

\footnotetext{
${ }^{2}$ Para maior compreensão quanto à metodologia empregada pelo Instituto, conferir V-DEM (2018b).
} 
adquire o poder de decidir, mediante uma luta competitiva, pelos votos do eleitor" (Schumpeter, 1961, p. 321).

Percebe-se que, para esta abordagem, os procedimentos de tomada de decisão são transformados em método para constituir um governo. A preocupação de Schumpeter (1961) com a formulação de um sistema coerente faz o autor depositar ao cargo das elites todas as prerrogativas para competir e conduzir os negócios públicos, deixando aos cidadãos apenas a liberdade para escolher os candidatos que tomarão as decisões em seu nome. Por isso é que Guillermo O’Donnell (2000) atribui o caráter "elitista" ao modelo de democracia schumpeteriano.

Ainda na mesma geração, inclui-se o ângulo de Robert Dahl (2005) que, também preocupado em definir a democracia como um regime político - ou seja, em suas regras institucionais e procedimentos para o exercício do poder -, faz uma crítica a Schumpeter (1961) ao reconhecer a participação para além das elites. Segundo Dahl (2005), a democracia é um modelo normativo que deveria permitir a responsividade entre governantes e governados, o que não ocorre na prática. Os exemplos da realidade evidenciam, em contraposição, a disputa constante entre diferentes atores pelo controle das decisões. Por isso, na medida em que se elevam as condições institucionais para que os indivíduos contestem as decisões políticas e possam ser incorporados à disputa pelo poder, maior seria a aproximação das poliarquias às expectativas do ideal democrático. Portanto, em Dahl (2005), as duas dimensões - contestação pública e participação política - delineiam o jogo democrático como equilíbrio de forças e servem de instrumentos para se avaliar o grau de democratização de um país.

A combinação dos pressupostos de Schumpeter (1961) e Dahl (2005) resultou no modelo procedural mínimo (Castro Santos, 2001), em que a democracia é posta como regime exercido por eleições regulares e livres, através das quais o cidadão dispõe de um arcabouço de direitos políticos e civis para participar da tomada de decisão. Larry Diamond (1999), por sua vez, qualifica o conceito schumpeter-dahlsiano como Democracia Eleitoral, dada a ênfase conferida aos pleitos em detrimento da problematização da qualidade da participação política, da prestação de contas e das liberdades para contestar e atuar nas esferas decisórias.

Por isso é que o conceito de Democracia Liberal surge como uma "proposta expandida" (Castro Santos, 2001), ou, por assim dizer, um esforço para acrescentar novos atributos ao modelo procedural mínimo. Herdeira do progresso liberal do século XIX e inspirada nas experiências norte-americanas da época, a Democracia Liberal ressurge na década de 1970 com Macpherson (1978) e, sob os contornos de Larry Diamond (1999), adquire sua maior expressividade. Para Diamond, a Democracia Liberal deve se ampliar o suficiente para incorporar os contrapesos constitucionais, a transparência política, a accountability, a liberdade de expressão, o pluralismo e a supremacia civil que, em certos aspectos, são descurados pela geração de Schumpeter e Dahl. Isso significa que este modelo associa o regime democrático como garantia dos direitos fundamentais e estabelece mecanismos para se evitar a usurpação do poder pelo Estado ou por grupos majoritários. Nas palavras do autor, a Democracia Liberal conforma

[...] primeiro, a ausência de domínios de poder reservados para os militares ou outros atores que não respondem diretamente ao eleitorado, direta ou indiretamente. Em segundo lugar, além da accountability vertical dos governantes aos governados (assegurada, principalmente, por meio de eleições), requer a responsabilidade horizontal dos titulares de cargos uns com os outros; isso restringe o Poder Executivo 
e, assim, ajuda a proteger o constitucionalismo, a legalidade e o processo deliberativo. Em terceiro lugar, abrange disposições extensas para o pluralismo político e cívico, bem como para as liberdades individuais e coletivas [...]. (Diamond, 1999, tradução nossa).

Em direção semelhante à de Diamond, o Instituto V-DEM, cujos indicadores serão empregados no trabalho em questão, define a Democracia Liberal como

[...] importância de proteger os direitos individuais e das minorias contra a tirania do Estado e a tirania da maioria. O modelo liberal adota uma visão "negativa" do poder político na medida em que julga a qualidade da democracia pelos limites impostos ao governo. Isto é conseguido através de liberdades civis constitucionalmente protegidas, um Estado de Direito forte, um sistema judiciário independente e contrapesos eficazes que, juntos, limitam o exercício do Poder Executivo (V-DEM, 2018b, tradução nossa).

Mas a atenção a que chamamos é a natureza do conceito de Democracia Liberal como parte das expectativas norte-americanas desde o Pós-Guerra Fria. Isso porque, ao se encerrar o conflito entre as superpotências, os Estados Unidos se depararam com uma nova realidade que, isenta das supostas ameaças comunistas, propiciou a Washington difundir amplamente os valores da tradição liberal. Por isso é que, como parte da sua consolidação hegemônica, a potência norte-americana conformou uma nova ordem internacional e pressionou os países a se adequarem ao exercício da democracia em questão. E, nesse sentido, a própria OEA demonstra seu viés ao hegemon quando apresenta sua compreensão de democracia muito semelhante à proposta liberal, como será analisado adiante.

Tem-se, portanto, um formato de democracia para a região conformado aos padrões estadunidenses e que não corresponde, obrigatoriamente, à realidade da América Latina. Todavia, mesmo com as críticas e desconfianças, a Democracia Liberal ainda é parâmetro para avaliar a consolidação dos regimes que emergiram da Terceira Onda, principalmente a partir da atuação de forças externas como a OEA, uma vez que sua compreensão é intimamente ligada ao modelo em pauta.

Mas a pergunta que se coloca é: pode-se promover a Democracia Liberal a partir de esforços internacionais? Para boa parte da literatura, sim, desde que presente certas condições. $O$ trabalho de Guillermo O’Donnell e Philippe Schmitter (1986) entende que a democratização por vias externas foi um fenômeno pouco notado ao longo do século XX. Isso porque as transições políticas da época ganharam palco em Estados altamente institucionalizados. Nesses locais, averiguou-se que os fatores domésticos - como os movimentos sociais, o desgaste econômico e os novos pactos entre civis e militares - impactaram decisivamente nas democratizações, de modo pouco sensível às influências externas.

Além disso, outro fator limitante foi a própria condição internacional da época. Com o intento de afastar a ameaça comunista no mundo ocidental, os Estados Unidos, hegemonia dos valores liberais, conferiam suporte tanto às ditaduras quanto aos governos democráticos, e as Instituições Internacionais de seu fomento - como a OTAN e, inclusive, a OEA - não dispunham de mecanismos para aplicar a condicionalidade democrática. Por isso é que, junto ao pressuposto de Farer (1996) sobre a ambivalência dessas forças internacionais, concluímos que a construção de democracias era 
tratada como aptidão eminentemente nacional durante a Guerra Fria, e as variáveis externas não recebiam atenção significativa pela maior parte da literatura (Camargo, 2018).

A partir dos anos 1990, com o advento da Nova Ordem Mundial, um conjunto de autores anglosaxões ponderou as forças internacionais como elementos importantes para a instalação dos governos democráticos. As democracias seriam factíveis e consolidáveis não somente por conta endógena, mas, também, a partir dos incentivos externos. Na abordagem feita por Castro Santos (2010), esta tendência conforma a "literatura da exportação de democracia".

Mas a noção a ser reconhecida deve avaliar as chances do efeito internacional sobre o processo de democratização - embora, como lembra Castro Santos (2010), a literatura não seja consensual. Por isso é que Laurence Whitehead (2005) admite que a influência externa seria determinante nos Estados "fracos" ou "falidos" do Pós-Guerra Fria, onde, dada a vulnerabilidade transnacional, a balança da democratização penderia para as variáveis exteriores. É evidente que esta abordagem serviu aos interesses norte-americanos nas operações do Afeganistão e do Iraque, tidos como países falidos e, por decorrência, vulneráveis à atuação de grupos terroristas, o que justificaria a mobilização das potências ocidentais para implantar estruturas democráticas capazes de promover a segurança regional.

As teses de Whitehead (2005), ao colocar a falência do Estado como variável condicional ao êxito da exportação de democracia, não explicam com pertinência a Terceira Onda na América Latina que, vale ressaltar, processou-se sob condições de elevada institucionalização. Boa parte de seus países, principalmente os da América do Sul, apresenta, historicamente, a marca da centralização estatal que, ao mesmo tempo, confere pouca abertura à participação popular e à fisscalização pública, assim como se intimida à vinculação automática aos interesses hegemônicos. E isso não significa negar o estímulo das variáveis externas, ainda que em graus variados, sobre o processo de consolidação das democracias latino-americanas, mas reconhecer neles as dificuldades de atuação para alcançar o resultado esperado - qual seja: a Democracia Liberal.

A partir das ideias acima, e com o suporte na geração mais recente da literatura - mesmo reconhecendo o viés norte-americano que a marca -, parece-nos coerente pressupor que os atores externos influem de alguma forma na consolidação das democracias e não podem ser negligenciados. Os regimes políticos demonstram cada vez mais a participação do externo na (re)configuração doméstica. E é por isso que as investigações, desde então, devem considerar não apenas os movimentos nacionais, mas as forças que partem do exterior.

Mas o trabalho desta investigação seria equivocado se alegasse os fatores internacionais - ou, mais precisamente, a OEA - como instrumentos que agem de maneira uniforme e exitosa para reverter as crises políticas e consolidar Democracias Liberais. Ao contrário, a problematização a ser feita deve considerar também os exemplos de ineficácia ou falhas nessa dinâmica. Isso nos sugere, portanto, que a nossa Variável Dependente, a própria “consolidação de democracia”, nem sempre apresentou os resultados esperados. Antes, no entanto, de apresentar e analisar tais resultados, faz-se necessário, no próximo tópico, entender a construção do propósito democrático da OEA, tomada como Variável Independente da pesquisa. 


\section{A estrutura de promoção da democracia liberal construída pela OEA}

A Organização dos Estados Americanos (OEA) emerge em 1948 como síntese de uma integração regional que data do século XIX. O imediato Pós-Guerra e a afirmação da bipolaridade mundial converteram a maior parte do continente em zona de alinhamento ao bloco capitalista e aos interesses da potência norte-americana. Por tal razão, era nítida a divergência entre EUA e os vizinhos do sul, na medida em que a Casa Branca defendia o fortalecimento do continente para rebater as ameaças soviéticas, e os latino-americanos focalizavam suas expectativas na promoção do desenvolvimento econômico e social (Ribeiro, 2006).

Durante a época, a preocupação central da OEA era consolidar uma noção compartilhada de segurança, pautada na militarização regional e na defesa de governos rígidos o suficiente, independente da natureza política, para afastar as ameaças do comunismo. Para Farer (1996), esta máxima evidenciou posturas ambíguas da OEA para com os regimes latino-americanos, já que dispensava o tratamento equivalente às democracias e às ditaduras. Como se percebe, a Organização indispunha de uma estrutura favorável aos regimes democráticos.

Nesse sentido é que o papel da OEA nas democratizações deve ser entendido na lógica do PósGuerra Fria. Isso porque a vitória do capitalismo norte-americano e a instauração da Nova Ordem Mundial não apenas conformaram expectativas otimistas quanto às transições da Terceira Onda, mas possibilitaram ao hegemon elevar a Democracia Liberal a um novo patamar, suficiente o bastante para se converter em princípio da convivência regional. Para Rubén Perina (2000), inicia-se, desde então, o que denomina de "Novo Rol da OEA".

Desse modo, já no Compromisso de Santiago com a Democracia Representativa e Renovação do Sistema Interamericano (OEA, 1991a), a OEA expressou ser a democracia "o regime de governo do continente", e seu exercício, promoção, consolidação e desenvolvimento seriam tomados como ações necessariamente compartilhadas. Por isso, mediante as alterações em curso na política regional da época, a Organização clamou a cooperação entre os Estados para delinear uma agenda unificada de respostas coletivas aos casos de abalos políticos (Acevedo e Grossman, 1996).

O instrumento que emergiu do propósito, no mesmo ano, foi a Resolução 1080. Em suas disposições, o documento conferiu ao Secretário Geral a incumbência de convocar extraordinariamente o Conselho Permanente, bem como a Assembleia Geral e a Reunião de Consulta dos Ministros das Relações Exteriores, mediante a interrupção súbita da ordem democrática, ou do exercício de poder de quaisquer governos constitucionais. Segundo as regras desta Resolução, as instâncias deveriam examinar os casos em pauta a fim de adotar medidas pertinentes e instruir alternativas para restaurar o regime ora em crise (OEA, 1991b).

O chamado Protocolo de Washington, assinado em 1992, inseriu um mecanismo mais severo ao dispor que, mediante a queda pela força de um governo constitucional, os países deliberariam a possibilidade de suspensão como último recurso, após a ineficácia de investiduras anteriores (OEA, 1992). O que notamos, a partir daqui, é a alocação da democracia como critério de legitimidade à participação na OEA (Cooper e Legler, 2001).

A essência da Resolução 1080 foi preservada pela Carta Democrática Interamericana (CDI), assinada em 2001, que veio compilar os acordos anteriores numa única concordata. Mas o reconhecimento a ser feito é que, a despeito da manutenção da condicionalidade democrática para a participação junto ao sistema interamericano, havia o silêncio da Organização quanto ao conceito de 
democracia exigido. Esta lacuna foi superada com a CDI, que estabeleceu categoricamente a seguinte noção:

Art. 3 São elementos essenciais da democracia representativa, entre outros, o respeito aos direitos humanos e às liberdades fundamentais, o acesso ao poder e seu exercício com sujeição ao Estado de Direito, a celebração de eleições periódicas, livres, justas e baseadas no sufrágio universal e secreto como expressão da soberania do povo, o regime pluralista de partidos e organizações políticas, e a separação e independência dos poderes públicos (OEA, 2001).

Como se pode notar, a ideia de democracia representativa enfatizada pela Carta assimila não apenas a representação política por meio do voto, exercido em eleições periódicas, livres e justas. Este é entendido como elemento fundacional do sistema político, através do qual a soberania do povo é expressada. Não obstante a marca eleitoral, a compreensão da CDI vai além, ao propor uma estrutura constitucional capaz de promover a independência e os contrapesos entre os Poderes, a pluralidade de partidos e expressões políticas, e garantir aos cidadãos o exercício de suas liberdades e direitos fundamentais.

No Artigo $4^{\circ}$, a CDI acrescenta a accountability como elemento fundamental. Segundo a Carta, o exercício democrático deve zelar pela transparência pública. Isso significa invocar aos governos a destreza republicana por meio da prestação de contas à sociedade, além de os responsabilizar pelas incoerências nos atos de gestão. Para o documento, a transparência governamental se efetiva concomitantemente à participação política, ao respeito aos direitos políticos e civis, bem como às liberdades (OEA, 2001).

Ainda concernente ao mesmo tópico, a CDI dispõe atenção aos casos orçamentários que envolvam custos elevados de campanhas eleitorais e de administração pública. Chama-se, novamente, o Estado à responsabilização pelos gastos públicos e sua prestação de contas. Para a OEA, o regime democrático demanda um exercício equilibrado entre receitas e despesas, que se fortalece com a transparência pública e confere sustentabilidade financeira ao governo (OEA, 2001).

Outro indicador que ampara o modelo democrático da OEA é a supremacia da ordem constitucional. Ainda no Artigo $4^{\circ}$, a CDI determina a subordinação de todas as instituições públicas à égide do poder constitucional estabelecido, necessariamente, pela autoridade civil. Nota-se, aqui, o esforço para deslegitimar governos militares, como também aqueles que, embora compostos por representantes civis, exerçam suas ações sob abuso de poder ou, ainda, sobrepostos ao Estado de Direito.

$\mathrm{Na}$ tabela a seguir, sintetizamos os pressupostos do modelo liberal, tal como proposto por Diamond (1999), junto aos principais indicadores de democracia enaltecidos pela OEA: 
Tabela 1 - Comparação entre os elementos do regime democrático para Larry Diamond e para a OEA

\begin{tabular}{|c|c|}
\hline $\begin{array}{l}\text { Pressupostos da Democracia Liberal para Diamond } \\
\text { (1999) }\end{array}$ & $\begin{array}{l}\text { Elementos fundamentais da democracia } \\
\text { representativa segundo a OEA (2001) }\end{array}$ \\
\hline $\begin{array}{c}\text { Ausência de poder reservado aos militares ou } \\
\text { autoridades não subordinadas à decisão eleitoral, } \\
\text { direta ou indiretamente. }\end{array}$ & $\begin{array}{l}\text { "A subordinação constitucional de todas as } \\
\text { instituições do Estado à autoridade civil legalmente } \\
\text { constituída e o respeito ao Estado de Direito por todas } \\
\text { as instituições e setores da sociedade são igualmente } \\
\text { fundamentais para a democracia" (Art. } 4^{\circ} \text { ). }\end{array}$ \\
\hline $\begin{array}{l}\text { Proteção da ordem constitucional, da legalidade e da } \\
\text { deliberação pública. }\end{array}$ & $\begin{array}{l}\text { "O exercício efetivo da democracia representativa é a } \\
\text { base do Estado de Direito e dos regimes } \\
\text { constitucionais dos Estados membros da Organização } \\
\text { dos Estados Americanos. } \\
\text { A democracia representativa reforça-se e aprofunda-se } \\
\text { com a participação permanente, ética e responsável } \\
\text { dos cidadãos em um marco de legalidade, em } \\
\text { conformidade com a respectiva ordem constitucional" } \\
\left(\text { Art. } 2^{\circ}\right) \text {. }\end{array}$ \\
\hline Accountability vertical. & $\begin{array}{l}\text { "São componentes fundamentais do exercício da } \\
\text { democracia a transparência das atividades } \\
\text { governamentais, a probidade, a responsabilidade dos } \\
\text { governos na gestão pública, o respeito dos direitos } \\
\text { sociais e a liberdade de expressão e de imprensa" (Art. } \\
4^{\circ} \text { ). }\end{array}$ \\
\hline $\begin{array}{c}\text { Accountability horizontal e contrapesos entre os } \\
\text { Podere. }\end{array}$ & $\begin{array}{l}\text { "São elementos essenciais da democracia } \\
\text { representativa, entre outros, [...] a separação e } \\
\left.\text { independência dos poderes públicos" (Art. } 3^{\circ}\right) \text {. }\end{array}$ \\
\hline $\begin{array}{l}\text { Garantia extensiva de pluralismo político e civil, } \\
\text { assim como das liberdades individuais e coletivas. }\end{array}$ & $\begin{array}{l}\text { "São elementos essenciais da democracia } \\
\text { representativa, entre outros, o respeito aos direitos } \\
\left.\text { humanos e às liberdades fundamentais [...]" (Art. } 3^{\circ}\right) \text {. } \\
\text { "[...]a celebração de eleições periódicas, livres, justas } \\
\text { e baseadas no sufrágio universal e secreto como } \\
\left.\text { expressão da soberania do povo" (Art. } 3^{\circ}\right) \text {. } \\
\text { "[...] regime pluralista de partidos e organizações } \\
\left.\text { políticas" (Art. } 3^{\circ}\right) \text {. } \\
\text { "O fortalecimento dos partidos e de outras } \\
\text { organizações políticas é prioritário para a } \\
\left.\text { Democracia" (Art. } 5^{\circ}\right) \text {. } \\
\text { "A participação dos cidadãos nas decisões relativas a } \\
\text { seu próprio desenvolvimento é um direito e uma } \\
\text { responsabilidade. É também uma condição necessária } \\
\text { para o exercício pleno e efetivo da democracia" (Art. } \\
6^{\circ} \text { ). }\end{array}$ \\
\hline
\end{tabular}

Fonte: Elaboração própria.

Como se nota na tabela, há indícios nítidos de equivalência entre os requisitos do modelo liberal de Democracia e o formato defendido pela OEA. Essas evidências não podem ser dissociadas da lógica de poder observada no sistema interamericano desde o Pós-Guerra Fria, em que a potência estadunidense passa a alocar o formato liberal de democracia como "the only game in town" (Fukuyama, 1991). Por isso, as avaliações que investiguem a promoção de democracia pela Organização devem considerar o formato específico da Democracia Liberal que, embora não apresentado sob este signo em seus documentos, demonstra, ontologicamente, a preservação dos elementos tal como propõe Larry Diamond (1999). 


\subsection{Instrumentos da OEA para promover a Democracia Liberal}

Traçado o modelo analítico para examinarmos a promoção de democracia, resta-nos, neste tópico, identificar os instrumentos à disposição da OEA para gerenciar as crises políticas desde 1990 e encaminhar tais governos às expectativas do modelo liberal. O levantamento desta pesquisa revelou a quantidade variada de instrumentos ao dispor da Organização que, para os fins analíticos, foram condensados em indicadores que apresentamos a seguir:

○ Apoio Moral/Político;

○ Condenação Moral/Política;

- CDI (Carta Democrática Interamericana);

- Convocação dos MREs (Convocação da Reunião de Consulta dos Ministros das Relações Exteriores);

○ Encaminhamento do caso ao CSNU (Conselho de Segurança das Nações Unidas);

○ Suspensão da participação junto à OEA;

- Mediações (mediação técnica ou mediação do Secretário Geral);

○ Missão Civil (missão de caráter não militar e de proteção aos civis);

○ Missão Técnica (observações especializadas, auxílio técnico, investigações ou avaliações do caso);

○ MOE (Missão de Observação Eleitoral);

○ Pressões Internacionais (recomendação a outros países e instituições não regionais para que reavaliassem suas relações com o país em crise e adotassem alguma medida restritiva);

○ Pressões Regionais (recomendação de embargos regionais, pressões diplomáticas, solicitação de restituição imediata dos antigos governantes ou respeito à ordem constitucional);

○ R. 1080 (Resolução 1080).

\section{Análise dos envolvimentos da OEA nas crises do Pós-Guerra Fria}

\subsection{Os indicadores de crise política}

Para a Ciência Política de viés institucionalista, pode-se afirmar que as crises políticas ocorrem quando as instituições estatais - dentre elas, principalmente, o Governo - são incapazes de interferir na instabilidade posta e reconduzi-la à normalidade (constitucional, partidária, representativa, dentre outras). Pasquino (2007) nos explica que as crises governamentais podem se originar de fatores internos ou externos ao governo.

Internamente, há de se reconhecer o grau de homogeneidade da estrutura governativa: quanto mais a coligação política for homogênea e a oposição estiver fragmentada e orientada a aceitar o sistema posto, de modo a não se instalar dicotomias extremistas, menores serão as chances de ocorrer uma crise política. No que tange aos fatores externos - ou seja, a relação entre a classe política e os grupos sociais - entende-se que a baixa ou ausência de representatividade, somada à incapacidade de responder com eficácia às pressões do sistema social, são elementos determinantes à instalação das crises políticas (Pasquino, 2007). 
Dentre os indicadores ao dispor do analista, a pesquisa em questão optou pelo emprego do instrumento desenvolvido por Marcelo Coutinho (2006). Em sua publicação Movimentos de Mudança Política na América do Sul Contemporânea, o autor investiga o número de crises institucionais e violências políticas que ocorrem na região dentro de períodos semestrais. Os resultados encaminham o Índice de Estabilidade Política (IEP), que varia entre $-1,0$ e $+1,0$. Quanto mais próximo ao valor positivo, mais estável é o caso investigado.

Julga-se pertinente este instrumento, uma vez que as variáveis analisadas por ele - quais sejam: crises institucionais e violências políticas - figuram agressões nítidas contra elementos caros à Democracia Liberal. No tocante à primeira dimensão, o descompasso - seja de origem interna ou externa, como apontado anteriormente - ocorrido em instituições como pleitos eleitorais, exercício constitucional, canais de accountability e na estrutura diversificada de representação denigrem diretamente a ordem liberal democrática. $\mathrm{O}$ mesmo pode ser verificado nas ocorrências de violência política, por ferir direitos como participação, representação, contestação pública e exercício das liberdades dos diferentes grupos, tidos como fundamentais ao exercício da Democracia Liberal.

Para significar uma instabilidade - ou crise política, de acordo com a nossa abordagem, as ocorrências devem apresentar pelo menos um dos indicadores que sintetizam as definições:

Tabela 2 - Indicadores de Instabilidade Política

\begin{tabular}{cc}
\hline INDICADOR & DEFINIÇÃO \\
\hline Golpe & Golpe, Atentado de Golpe, Contragolpe \\
Guerra Civil & Avanço de guerrilhas, ataques maciços, violação de acordos, choque de tropas, \\
assassinato de autoridades. \\
Estado de & Declaração ou extensão de Estado de Emergência em escala nacional, departamento \\
Emergência & província ou estado com mais de 100.000 habitantes. \\
Interrupção do & Impeachment, resignação, antecipação de eleições. \\
Mandato & \\
Presidencial & Violência contra o governo central e implicação de 100 feridos ao mínimo. \\
Revolta Social & Fonte: Elaborado a partir de Coutinho (2010).
\end{tabular}

\subsection{Resultados do envolvimento da OEA nas crises do Pós-Guerra Fria}

$\mathrm{Na}$ tabela a seguir, organizamos os resultados colhidos com a pesquisa. A matriz de dados organiza 31 ocorrências de crises políticas investigadas de acordo com o período e país de ocorrência, a natureza da instabilidade e as principais medidas adotadas pela OEA. A qualidade do regime democrático de cada estudo é avaliada com base no Liberal Democratic Index (V-DEM, 2018b), com registros do ano imediatamente anterior e imediatamente posterior à crise:

Tabela 3 - Crises políticas e resultados da promoção de democracia pela OEA

\begin{tabular}{|c|c|c|c|c|c|c|}
\hline Ano & País & Evento & $\begin{array}{c}\text { Modalidade de } \\
\text { crise }\end{array}$ & Principais medidas da $O E A$ & $\begin{array}{c}\text { Liberal } \\
\text { Democracy } \\
\text { Index } \\
\text { Anterior }\end{array}$ & $\begin{array}{c}\text { Liberal } \\
\text { Democracy } \\
\text { Index } \\
\text { Posterior }\end{array}$ \\
\hline 1990-91 & SURINAME & Golpe de Estado & Golpe & MOE & 0,55 & 0,67 \\
\hline 1991-94 & HAITI & Golpe de Estado & Golpe & $\begin{array}{l}\text { 1) R. 1080; 2) Pressões } \\
\text { Regionais; 3) Pressões } \\
\text { Internacionais; 4) Missão } \\
\text { Técnica; 5) Missão Civil } \\
\text { OEA-DEMOC; 6) }\end{array}$ & 0,08 & 0,25 \\
\hline
\end{tabular}




\begin{tabular}{|c|c|c|c|c|c|c|}
\hline Ano & País & Evento & $\begin{array}{l}\text { Modalidade de } \\
\text { crise }\end{array}$ & Principais medidas da OEA & $\begin{array}{c}\text { Liberal } \\
\text { Democracy } \\
\text { Index } \\
\text { Anterior }\end{array}$ & $\begin{array}{l}\text { Liberal } \\
\text { Democracy } \\
\text { Index } \\
\text { Posterior }\end{array}$ \\
\hline & & & & $\begin{array}{l}\text { Encaminhamento do caso ao } \\
\text { CSNU; 7) Missão MICIVIH } \\
\text { (com ONU) }\end{array}$ & & \\
\hline 1992 & VENEZUELA & Golpes de Estado & Golpe & $\begin{array}{l}\text { 1) Pressões Regionais; 2) } \\
\text { Pressões Internacionais; 3) } \\
\text { Missão Técnica }\end{array}$ & 0,66 & 0,66 \\
\hline 1992 & PERU & Auto-Golpe & Golpe & $\begin{array}{l}\text { 1) R. 1080; 2) Solicitação de } \\
\text { restituição imediata; 3) } \\
\text { Pressões Internacionais; 4) } \\
\text { Pressões Regionais; 5) } \\
\text { Mediação; 6) Missão } \\
\text { Técnica; 7) Declaração de } \\
\text { Bahamas }\end{array}$ & 0,43 & 0,11 \\
\hline 1993 & GUATEMALA & Auto-Golpe & Golpe & $\begin{array}{l}\text { 1) R. 1080; 2) Pressões } \\
\text { Regionais; 3) Pressões } \\
\text { Internacionais; 4) Mediação. }\end{array}$ & 0,21 & 0,23 \\
\hline 1996 & PARAGUAI & Golpe de Estado & Golpe & $\begin{array}{l}\text { 1) R. 1080; 2) Mediação; 3) } \\
\text { Missão Técnica }\end{array}$ & 0,38 & 0,4 \\
\hline 1997 & EQUADOR & Impeachment & $\begin{array}{l}\text { Interrupção do } \\
\text { Mandato } \\
\text { Presidencial }\end{array}$ & $\begin{array}{l}\text { 1) Disposição em auxílio } \\
\text { técnico; 2) MOE-98 }\end{array}$ & 0,49 & 0,5 \\
\hline 1998 & PARAGUAI & Ameaça de Golpe & Golpe & $\begin{array}{l}\text { 1) Condenação } \\
\text { Moral/Política }\end{array}$ & 0,39 & 0,41 \\
\hline 2000 & EQUADOR & $\begin{array}{l}\text { Renúncia do } \\
\text { Cargo }\end{array}$ & $\begin{array}{l}\text { Interrupção do } \\
\text { Mandato } \\
\text { Presidencial }\end{array}$ & $\begin{array}{c}\text { 1) Condenação } \\
\text { Moral/Política; 2) Pressões } \\
\text { Internacionais; 3) Auxílio a } \\
\text { presidente interino para sua } \\
\text { saída }\end{array}$ & 0,49 & 0,48 \\
\hline 2000 & PARAGUAI & Ameaça de Golpe & Golpe & $\begin{array}{c}\text { 1) Condenação } \\
\text { Moral/Política; 2) } \\
\text { Disposição em assistência } \\
\text { técnica }\end{array}$ & 0,41 & 0,43 \\
\hline 2001-04 & HAITI & $\begin{array}{c}\text { Renúncia do } \\
\text { Cargo e Revoltas } \\
\text { Sociais }\end{array}$ & $\begin{array}{l}\text { Interrupção do } \\
\quad \text { Mandato } \\
\text { Presidencial e } \\
\text { Revoltas Sociais }\end{array}$ & $\begin{array}{l}\text { 1) CDI; 2) Mediação; 3) } \\
\text { Encaminhamento do caso ao } \\
\text { CSNU); 4) Missão } \\
\text { MINUSTAH }\end{array}$ & 0,29 & 0,09 \\
\hline 2002 & VENEZUELA & Golpe de Estado & Golpe & 1) CDI; 2) Mediação & 0,31 & 0,26 \\
\hline 2003 & BOLÍVIA & $\begin{array}{l}\text { Renúncia do } \\
\text { Cargo }\end{array}$ & $\begin{array}{l}\text { Interrupção do } \\
\text { Mandato } \\
\text { Presidencial }\end{array}$ & $\begin{array}{l}\text { 1) Apoio Moral/Político a } \\
\text { ambos os presidentes }\end{array}$ & 0,54 & 0,55 \\
\hline 2004 & EQUADOR & $\begin{array}{l}\text { Estado de } \\
\text { Emergência e } \\
\text { Impeachment }\end{array}$ & $\begin{array}{c}\text { Estado de } \\
\text { Emergência e } \\
\text { Interrupção do } \\
\text { Mandato } \\
\text { Presidencial }\end{array}$ & $\begin{array}{l}\text { 1) Solicitação de respeito à } \\
\text { ordem democrática; 2) } \\
\text { Missão Técnica }\end{array}$ & 0,51 & 0,52 \\
\hline 2004 & PERU & $\begin{array}{l}\text { Estado de } \\
\text { Emergência }\end{array}$ & $\begin{array}{l}\text { Estado de } \\
\text { Emergência }\end{array}$ & 1) Pressão Regional & 0,65 & 0,64 \\
\hline 2005 & BOLÍVIA & $\begin{array}{l}\text { Renúncia do } \\
\text { Cargo }\end{array}$ & $\begin{array}{l}\text { Interrupção do } \\
\text { Mandato } \\
\text { Presidencial }\end{array}$ & 1) MOE-2005 & 0,55 & 0,49 \\
\hline 2005 & NICARÁGUA & Ameaça de Golpe & Golpe & $\begin{array}{l}\text { 1) Disposição em auxílio } \\
\text { técnico; 2) Missão Técnica; } \\
\text { 3) Condenação } \\
\text { Moral/Política }\end{array}$ & 0,43 & 0,38 \\
\hline 2008 & BOLÍVIA & $\begin{array}{c}\text { Revoltas Sociais e } \\
\text { Estado de } \\
\text { Emergência }\end{array}$ & $\begin{array}{l}\text { Revoltas Sociais } \\
\text { e Estado de } \\
\text { Emergência }\end{array}$ & $\begin{array}{l}\text { 1) Pressões Regionais; 2) } \\
\text { Mediação }\end{array}$ & 0,48 & 0,46 \\
\hline 2009 & HONDURAS & Golpe de Estado & Golpe & $\begin{array}{l}\text { 1) CDI; 2) Condenação } \\
\text { Moral/Política; 3) Suspensão } \\
\text { da participação }\end{array}$ & 0,34 & 0,28 \\
\hline
\end{tabular}




\begin{tabular}{|c|c|c|c|c|c|c|}
\hline Ano & País & Evento & $\begin{array}{l}\text { Modalidade de } \\
\text { crise }\end{array}$ & Principais medidas da OEA & $\begin{array}{l}\text { Liberal } \\
\text { Democracy } \\
\text { Index } \\
\text { Anterior }\end{array}$ & $\begin{array}{c}\text { Liberal } \\
\text { Democracy } \\
\text { Index } \\
\text { Posterior }\end{array}$ \\
\hline 2012 & PARAGUAI & Impeachment & $\begin{array}{l}\text { Interrupção do } \\
\text { Mandato } \\
\text { Presidencial }\end{array}$ & $\begin{array}{l}\text { 1) Mediação; 2) Missão } \\
\text { Técnica }\end{array}$ & 0,52 & 0,43 \\
\hline 2014 & HAITI & $\begin{array}{l}\text { Atraso nas } \\
\text { eleições }\end{array}$ & $\begin{array}{l}\text { Interrupção do } \\
\text { Mandato } \\
\text { Presidencial }\end{array}$ & 1) Missão Técnica; 2) MOE & 0,27 & 0,26 \\
\hline 2014 & $\begin{array}{c}E L \\
\text { SALVADOR }\end{array}$ & $\begin{array}{l}\text { Crítica da } \\
\text { oposição aos } \\
\text { resultados } \\
\text { eleitorais }\end{array}$ & $\begin{array}{l}\text { Golpe (atentado } \\
\text { de Golpe) }\end{array}$ & $\begin{array}{l}\text { 1) MOE; 2) Apoio } \\
\text { Moral/Político ao novo } \\
\text { governo }\end{array}$ & 0,46 & 0,48 \\
\hline 2014 & VENEZUELA & Revoltas Sociais & Revoltas Sociais & 1) Apoio Moral/Político & 0,13 & 0,12 \\
\hline 2015 & GUATEMALA & $\begin{array}{l}\text { Renúncia e } \\
\text { condenação do } \\
\text { presidente }\end{array}$ & $\begin{array}{l}\text { Interrupção do } \\
\text { Mandato } \\
\text { Presidencial }\end{array}$ & $\begin{array}{l}\text { 1) MOE; 2) Apoio } \\
\text { Moral/Político }\end{array}$ & 0,43 & 0,52 \\
\hline 2015 & HAITI & $\begin{array}{l}\text { Atraso nas } \\
\text { eleições }\end{array}$ & $\begin{array}{l}\text { Interrupção do } \\
\text { Mandato } \\
\text { Presidencial }\end{array}$ & $\begin{array}{l}\text { 1) MOE; 2) Condenação } \\
\text { Moral/Política }\end{array}$ & 0,27 & 0,26 \\
\hline 2016 & HAITI & $\begin{array}{l}\text { Atraso nas } \\
\text { eleições }\end{array}$ & $\begin{array}{l}\text { Interrupção do } \\
\text { Mandato } \\
\text { Presidencial }\end{array}$ & $\begin{array}{l}\text { 1) MOE; 2) Apoio } \\
\text { Moral/Político }\end{array}$ & 0,26 & $\mathrm{~S} / \mathrm{D}^{*}$ \\
\hline 2016 & COLÔMBIA & $\begin{array}{l}\text { Acordo de Paz } \\
\text { entre Governo e } \\
\text { FARCs }\end{array}$ & Acordo de Paz & Apoio Moral/Político & 0,50 & 0,49 \\
\hline 2016 & VENEZUELA & $\begin{array}{l}\text { Estado de } \\
\text { Emergência }\end{array}$ & $\begin{array}{c}\text { Estado de } \\
\text { Emergência, } \\
\text { Guerra Civile } \\
\text { Revoltas Sociais }\end{array}$ & $\begin{array}{l}\text { 1) Condenação } \\
\text { Moral/Política; 2) Mediação }\end{array}$ & 0,12 & 0,12 \\
\hline 2017 & VENEZUELA & $\begin{array}{l}\text { Anulação do } \\
\text { Legislativo }\end{array}$ & $\begin{array}{l}\text { Golpe, Guerra } \\
\text { Civil e Revoltas } \\
\quad \text { Sociais }\end{array}$ & $\begin{array}{c}\text { 1) Condenação } \\
\text { Moral/Política; 2) Pressões } \\
\text { Regionais; 3) Convocação } \\
\text { dos MREs }\end{array}$ & 0,15 & $\mathrm{~S} / \mathrm{D}^{*}$ \\
\hline 2018 & NICARÁGUA & $\begin{array}{l}\text { Recrudescimento } \\
\text { do Governo } \\
\text { Ortega e } \\
\text { perseguições aos } \\
\text { opositores }\end{array}$ & $\begin{array}{c}\text { Guerra Civil; } \\
\text { Revoltas Sociais }\end{array}$ & $\begin{array}{c}\text { 1) Condenação } \\
\text { Moral/Política; 2) Missão } \\
\text { Técnica; 3) Missão Civil } \\
\text { (Grupo de Peritos } \\
\text { Independentes); 4) MOE }\end{array}$ & 0,12 & $\mathrm{~S} / \mathrm{D}^{*}$ \\
\hline 2018 & VENEZUELA & $\begin{array}{l}\text { Reeleição de } \\
\text { Nicolás Maduro }\end{array}$ & $\begin{array}{l}\text { Golpe, Guerra } \\
\text { Civil e Revoltas } \\
\text { Sociais }\end{array}$ & $\begin{array}{l}\text { 1) Condenação } \\
\text { Moral/Retórica; 2) Pressões } \\
\text { Regionais; 3) CDI; 4) MOE }\end{array}$ & 0,12 & $\mathrm{~S} / \mathrm{D}^{*}$ \\
\hline
\end{tabular}

Fonte: elaborada pelo autor.

* $\mathrm{S} / \mathrm{D}=$ Sem Dados publicados até o fechamento deste artigo.

Os resultados demonstram aspectos reveladores quanto à promoção de democracia pela OEA. Primeiramente, nota-se que os Golpes e as Interrupções de Mandatos Presidenciais são as formas de crises mais frequentes no período analisado. Não obstante sua recorrência, há de se reconhecer, nelas, os contextos mais desafiadores enfrentados pela OEA, exigindo, por parte desta, um esforço demasiado, e ao mesmo tempo preciso, para o resgate da ordem doméstica.

Nas ocasiões de Golpe em que a Organização aplicou a Resolução 1080, notou-se maior consenso e objetividade em torno das ações imediatas e forçosas à subversão das rupturas políticas (Cooper e Legler, 2001). A mesma tendência manteve-se a partir dos anos 2000, quando passou a vigorar a Carta Democrática Interamericana. Sua capacidade de mobilizar imediatamente a coletividade hemisférica tornou-se um recurso que conferiu ao Secretário Geral maior prerrogativa e abertura para intervir de forma diplomática entre as partes em conflito. Por isso, mediante a quebra 
nítida da regularidade constitucional-democrática nos casos investigados, notamos respostas imediatas e corretivas pela Organização.

Por outro lado, as incidências de impeachment, renúncia presidencial ou resignação nos revela o emprego de recursos enfáticos, porém não imediatos, uma vez que nem todos despertaram a aplicação da Resolução 1080 ou da Carta Democrática Interamericana. Nas ocorrências de Estado de Emergência, Guerra Civil e Revoltas Sociais, claramente se nota uma reação menos direta ou objetiva da OEA. Tais crises foram conduzidas, em sua grande parte, de maneira discursiva e recomendatória, pouco capaz de atingir o consenso entre os representantes da região quanto a instrumentos para além da retórica.

Sobre esse aspecto, Craig Arcenaux e David Pion-Berlin (2007) propõem que, nos contextos em que as crises são incertas - ou, melhor dizendo, quando há falta de informações claras sobre o que gerou a tensão política num determinado país e os desdobramentos destas - a OEA tem dificuldades para avaliar o cenário, seus efeitos e custos às estratégias. Por isso é que reluta em se envolver de forma mais direta. Os estudos de caso demonstraram esta afirmativa, já que, onde houve um rompimento evidente da institucionalidade democrática, como na maioria dos Golpes e em algumas Interrupções de Mandatos, a OEA tendeu a reconhecer com facilidade a "ameaça” e, por tal razão, envolveu-se com maior expressividade nessas crises.

Outro aspecto revelador da pesquisa diz respeito à qualidade das democracias após o envolvimento da OEA. Nesse sentido, podemos agrupar os casos em três grupos: os que tiveram melhora no Liberal Democracy Index, os que não variaram tal índice e, por fim, os que apresentaram redução do mesmo. Proporcionalmente, os casos de manutenção e diminuição foram maiores que o primeiro grupo, como demonstrado na tabela a seguir:

Tabela 4 - Variações no Liberal Democracy Index após o envolvimento da OEA

\begin{tabular}{ccc}
\hline Tendência & Quantidade de casos & Proporção (em relação ao total) \\
\hline $\begin{array}{c}\text { Aumento do Liberal Democracy } \\
\text { Index }\end{array}$ & 11 & $35,5 \%$ \\
$\begin{array}{c}\text { Manutenção do Liberal } \\
\text { Democracy Index }\end{array}$ & 2 & $6,5 \%$ \\
$\begin{array}{c}\text { Diminuição do Liberal } \\
\text { Democracy Index }\end{array}$ & 14 & $45,1 \%$ \\
Casos de imprecisão* & 4 & $12,9 \%$ \\
\hline
\end{tabular}

Fonte: Elaboração própria.

*Casos em que não existem dados fornecidos pelo V-DEM até o fechamento da pesquisa. Encontram-se dispostos na Tabela 3 com a indicação "S/D".

Os dados revelam que a tendência da promoção de democracia pela OEA é diminuir o Índice de Democracia Liberal do país. Apesar dos casos em que os esforços da Organização resultaram em elevação significativa do Index - a saber: Suriname (1990-91), Haiti (1991-94) e Guatemala (2015) -, devemos entendê-los como exceções num contexto regional marcado por Democracias Liberais de baixa qualificação.

E, nesse sentido, a OEA evidencia aspecto falho na promoção deste fim, já que os governos mantiveram a condição destoante da expectativa. Este é um debate caro à literatura de promoção e exportação de democracia (Castro Santos, 2001), sobretudo porque esta força externa - a OEA apresenta-se como incapaz de cumprir o propósito democrático que sustenta. Se a Organização não 
consegue interferir na dinâmica dos Estados para atingir a expectativa mencionada, pode-se entender que a mesma tende à ineficácia.

Stephen Krasner (2013) já afirmara que a incoerência entre os elementos normativos das Organizações Internacionais e os resultados que promovem expressaria o desgaste institucional. E é o que se verifica na prática com a OEA. Sua promoção de democracia foi efetiva ao criar princípios e normas quanto a um valor comum para o continente, além de responsabilizar a coletividade para atingi-lo. Seus instrumentos para ação preventiva e corretiva aos contextos de crise política, contudo, enaltecem desconcerto ou ineficácia para atingir os fins a que visa. Quando identificamos os resultados de Democracias Liberais distantes dos valores médios ou ótimos, remetemos à incoerência entre os aspectos mais normativos da Organização e os recursos que fornece ou propõe aos Estados. Assim, diferentemente das expectativas, a Democracia Liberal de alta qualidade dificilmente é atingida a partir das intervenções regionais e isso ressalta, novamente, a inconsistência entre princípios e ações.

\section{Gráfico 1 - Qualidade das Democracias Liberais geradas pela OEA} após envolvimento em situações de crise

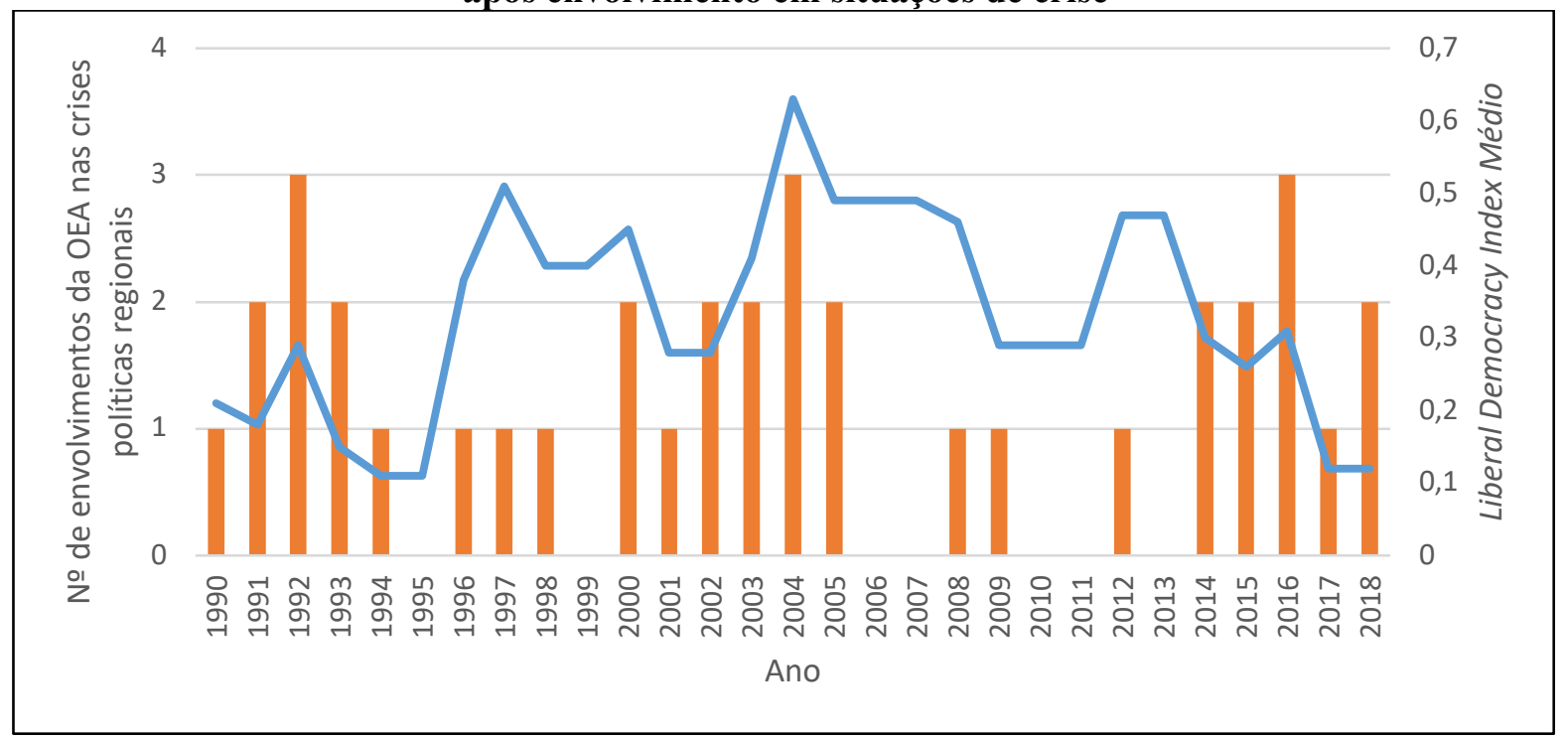

Fonte: Elaboração própria.

O Gráfico 1 organiza, dentro do recorte temporal investigado, o número de envolvimentos da OEA e a qualidade das democracias resultantes, de acordo com o Índice V-DEM. E, a partir dele, três grandes períodos podem ser distintos. Percebe-se que, na década de 1990, a maior atuação da OEA provocou a redução no Índice e, nas situações de menor envolvimento da Organização, houve a elevação na qualidade da Democracia Liberal. Nos anos 2000, um cenário adverso é constatado: a maior participação da OEA foi acompanhada pela elevação no Índice Médio da Democracia Liberal. Por fim, no último período - que compreende os anos de 2010 a 2018 -, observa-se a mesma tendência dos anos 1990: a relação inversa entre a presença da OEA e a qualidade da Democracia Liberal. Nesse sentido, a promoção de democracia investigada demonstra uma realidade assimétrica da qual, no entanto, podemos esperar uma tendência de que o contato da Organização nos cenários de crises, em vez de elevar, diminui a qualidade liberal dos regimes democráticos. 


\section{Conclusão}

Apesar da euforia otimista, a Terceira Onda na América Latina foi marcada por entraves que dificultaram a consolidação dos regimes democráticos em direção ao modelo liberal. Como se discutiu anteriormente, os desdobramentos da consolidação dos novos regimes incitaram a edificação de um quadro normativo na OEA, que fixou a Democracia Liberal como compromisso regional e se capacitou a atuar mediante a ameaças ou rupturas da ordem democrática. Este envolvimento regional, vale frisar, mostrou-se reentrante no Pós-Guerra Fria, especialmente a partir de 1991, quando houve o reconhecimento nítido dos dilemas e instabilidades que iriam de encontro à consolidação dos governos recém construídos.

A amostra deste estudo demonstrou a existência de crises democráticas com naturezas distintas, tais como Golpes, Interrupção do Mandato Presidencial, Estado de Emergência, Revoltas Sociais e Guerras Civis, sendo as duas primeiras proporcionalmente superiores às demais. Para analisá-las, levantamos uma amostra de 31 crises políticas, entre 1990 e 2018, marcadas pela intervenção da OEA. Todas foram examinadas quanto às medidas adotadas pela Organização, bem como pelos resultados da qualidade das democracias após o envolvimento da OEA, avaliadas segundo o Liberal Democracy Index. Tal investigação permitiu extrair duas principais evidências:

1) A OEA não atua igualmente em todas as crises democráticas. A análise revelou uma distinção clara dos envolvimentos da Organização nas crises. Nos casos de ruptura abrupta da institucionalidade democrática - em sua maioria Golpes e Interrupção do Mandato Presidencial -, a OEA atuou de forma direta - seja através de missões ou acompanhamento presencial -, corretiva politicamente enfática e com medidas punitivas que levam à suspensão - e objetiva - isto é, categórica em seu envolvimento. Especialmente nos contextos em que se aplicou a Resolução 1080 ou a Carta Democrática Interamericana, outro elemento foi somado às diferentes atuações: a instantaneidadeou seja, o trato emergencial do caso.

Por outro lado, nos casos em que os abalos não interromperam a ordem democráticoconstitucional, o envolvimento da Organização se deu através de recomendações, encorajamento ou condenação moral, dada as incertezas quanto à legalidade ou legitimidade dessas ocorrências, que dificultaram um possível consenso regional quanto a medidas concretas para a intervenção da entidade.

2) A qualidade liberal dos regimes democráticos, após a atuação da OEA, tende a ser baixa. Em vez da elevação do Índice de Democracia Liberal - que, vale ressaltar, foi observado, ainda que de modo sutil, em alguns casos - o que notamos com a pesquisa foi a tendência da redução do Índice. Os períodos compreendidos entre 1990 e 2000, assim como entre 2010 e 2008 demonstraram uma lógica semelhante que inverte a relação entre as duas variáveis. Ou seja, a maior participação da OEA provocou a redução do Índice investigado - o que não ocorreu no período entre 2000 e 2010.

Mas, apesar das assimetrias constatadas, certa tendência pode ser inferida. Se o grande propósito das Ciências Sociais - e, por decorrência, da própria Ciência das Relações Internacionais é produzir inferências, a partir do exame das tendências entre os fenômenos observados (King, Keohane e Verba, 1994), correlação se depreende a partir do exame entre o envolvimento da OEA (Variável Independente) e a consolidação de democracia (Variável Dependente) que, em nossa pesquisa, apresentou, em sua maioria, baixos valores para a qualificação liberal. Isso significa que, 
quanto mais frequentes a presença da OEA nos contextos de crises políticas, pode-se esperar Democracias Liberais com baixo índice. Dessa forma, chegamos à hipótese conclusiva, por meio da inferência descritiva, de que a OEA tende a promover democracias com baixa qualidade liberal.

\section{Referências}

ACEVEDO, Domingo; GROSSMAN, Claudio. The Organization of American States and the Protection of Democracy. In: FARER, Tom (Ed.). Beyond Sovereignty: collectively defending democracy in the Americas. Baltimore/London: The Johns Hopkins University Press, 1996.

ARCENAUX, Craig; PION-BERLIN, David. Issues, Threats, and Institutions: Explaining OAS Responses to Democratic Dilemmas in Latin America. Latin American Politics and Society, v. 49, n. 2, p. 1-31, 2007.

CAMARGO, Alan G. A promoção de democracia por meio de regimes: análise da atuação da Organização dos Estados Americanos (OEA) nas crises políticas do Pós-Guerra Fria. In: XI Encontro da Associação Brasileira de Ciência Política (ABCP). Curitiba, 2018.

- Democratizando a Democracia? A Promoção de Democracia por meio do Regime Democrático Interamericano. Dissertação de Mestrado. Universidade de Brasília, 2013.

CASTRO SANTOS, Maria Helena. O processo de democratização da Terceira Onda de Democratização: quanto pesam as variáveis externas? Boletim Meridiano 47, n. 115, p.15-18, 2010.

Que Democracia? Uma visão conceitual desde a perspectiva dos países em desenvolvimento. Dados, v. 44, n. 4, p. 729-771, 2001.

COOPER, Andrew; LEGLER, Thomas. The OAS Solidarity Paradigm: questions of Collective and National Leadership. Latin American Politics and Society, v. 43, n. 2, p.103-126, 2001.

COUTINHO, Marcelo. Movimentos de Mudança Política na América do Sul. Revista de Sociologia e Política, v. 27, p. 107-123, 2006.

DAHL, Robert. Poliarquia: participação e oposição. São Paulo: Ed. USP, 2005.

DIAMOND, Larry. Developing Democracy: Toward Consolidation. Baltimore/London: The Johns Hopkins University Press, 1999.

FARER, Tom. Collectively Defending Democracy in the Western Hemisphere: Introduction and Overview. In: (Org.). Beyond Sovereignty: Collectively Defending Democracy in the Americas. Baltimore/London: The Johns Hopkins University Press, 1996.

FUKUYAMA, Francis. Liberal Democracy as a Global Phenomenon. Political Science \& Politics, v. 24, n. 4, p. 659-664, 1991.

HUNTINGTON, Samuel. A Terceira Onda: a democratização no final do século XX. São Paulo: Ática, 1994.

KING, Gary; KEOHANE, Robert O.; VERBA, Sidney. Designing Social Inquiry. Princeton: Princeton University Press, 1994.

KRASNER, Stephen (Ed.). International Regimes. Ithaca/London: Cornell University Press, 1983. 
LAISNER, Regina C. A participação em questão: ponto ou contraponto da representação na teoria democrática? Revista Estudos de Sociologia, v. 14, n. 26, p. 17-35, 2009.

MACPHERSON, Crawford B. A democracia liberal: origens e evolução. Rio de Janeiro: Zahar, 1978.

O’DONNELL, Guillermo. Teoría Democrática y Política Comparada. Desarrollo Económico, v. 39, n. 156, p. 519-570, 2000.

. Uma outra institucionalização: América Latina e alhures. Lua Nova, n. 37, p. 5-32, 1996.

O’DONNELL, Guillermo; SCHMITTER, Philippe. Transitions from Authoritarian Rule: tentative conclusions about uncertain democracies. Baltimore/London: The Jonhs Hopkins University Press, 1986.

ORGANIZAÇÃO DOS ESTADOS AMERICANOS. Carta Democrática Interamericana [Online]. Lima, 2001. Disponível em:

$<$ http://www.oas.org/OASpage/eng/Documents/Democractic Charter.htm>. Acesso em: 18 jan.

2018.

. Protocolo de Reforma da Carta da Organização dos Estados Americanos [Online].

Protocolo de Washington. Washington, 1992. Disponível em:

$<$ http://www.oas.org/juridico/portuguese/treaties/A-56.htm>. Acesso em: 18 jun. 2018.

. Compromisso de Santiago com a Democracia Representativa e a Renovação do Sistema Interamericano [Online]. Santiago, 1991a. Disponível em:

$<$ http://www.oas.org/en/sla/docs/ag03805E01.pdf>. Acesso em: 18 jun. 2018.

. Representative Democracy [Online]. Resolução 1080. Santiago, 1991b. Disponível em:

<http://www.oas.org/en/sla/docs/ag03805E01.pdf>. Acesso em: 10 jan. 2013.

PASQUINO, Gianfranco. Crise. In: BOBBIO, Norberto; MATTEUCCI, Nicola; PASQUINO, Gianfranco. Dicionário de Política. Brasília: Editora UnB, 2007. v. 2.

PERINA, Rubén. El régime democrático interamericano: el papel de la OEA. In: TICKNER, Arlene B. (Org.). Sistema interamericano y democracia: antecedentes históricos y tendencias futuras. Bogotá: Ediciones Uniandes, 2000.

POLITY. Global Report 2017: Conflict, Governance and State Fragility [Online]. Disponível em: $<$ http://www.systemicpeace.org/vlibrary/GlobalReport2017.pdf>. Acesso em: 18 mar. 2019.

RIBEIRO, Eliane U. Consolidando a democracia: a eficiência da observação eleitoral da OEA: Haiti e Nicarágua. Trabalho de Conclusão de Curso. Universidade Estadual Paulista, 2006.

SCHUMPETER, Joseph. Capitalismo, Socialismo e Democracia. Rio de Janeiro: Fundo de Cultura, 1961.

V-DEM. Structure of V-Dem Indices, Components, and Indicators. University of Gothenburg Sprängkullsgatan: Gothenburg, 2018a. . Methodology. University of Gothenburg Sprängkullsgatan: Gothenburg, 2018b.

WHITEHEAD, Laurence. Freezing the Flow: Theorizing about Democratization in a World in Flux. Taiwan Journal of Democracy, v. 1, n. 1, p. 1-20, 2005. 
Alan Gabriel Camargo (camargo.irel@gmail.com) é Mestre em Relações Internacionais pela Universidade de Brasília (UnB).

\title{
A Promoção de Democracia Liberal pela OEA: o que esperar?
}

Resumo. O artigo em questão tem o objetivo de analisar os resultados da promoção de Democracia Liberal empreendida pela OEA após seu envolvimento nas crises políticas da América Latina. Para isso, investiga-se uma amostra composta por 31 casos, contextualizados entre 1990 e 2018, extraindo deles os impactos que a presença da Organização gerou à qualidade dos regimes democráticos. Os resultados da investigação levantam duas constatações: 1) A OEA não atua igualmente em todas as crises democráticas, tendo como premissa a natureza da crise; e 2) A qualidade dos regimes democráticos, após a atuação da OEA, destoa da expectativa traçada pela Organização. A partir desse exame, traça-se a hipótese conclusiva de que a OEA tende a promover democracias com baixo predicado liberal.

Palavras-chave: Organização dos Estados Americanos (OEA); Democracia Liberal; Crises políticas; Promoção de Democracia Liberal.

\section{The Defense of Liberal Democracy by OAS: what to expect?}

\begin{abstract}
The present paper aims to analyze the implications of Liberal Democracy promotion applied by Organization of American States (OAS) on Latin American political crises. For this purpose, a range of 31 cases during 1990 and 2018 are investigated and analyzed according to the quality of Liberal Democracy after OAS presence. The results lead to two conclusions: 1) OAS doesn't deal equally in every political crisis, bearing in mind the nature of crises; 2) democracy regimes promoted by OAS don't attend to its liberal prospect. After this recognition, the conclusive hypothesis points that OAS tends to promote low-quality Liberal Democracy.
\end{abstract}

Keywords: Organization of American States (OAS); Liberal Democracy; Political Crisis; Liberal Democratic Promotion. 